\title{
B CHROMOSOME SELECTION IN LOLIUM
}

\author{
S. B. TEOH, H. REES and J. HUTCHINSON \\ Department of Agricultural Botany, University College of Wales, Aberystwyth
}

Received 17.ii.76

\begin{abstract}
SUMMARY
Populations of Lolium perenne carrying B chromosomes were sown at densities ranging from 5 to 100 per pot. At the end of the first year of growth the proportion of plants with B's among the survivors increased in conjunction with the increasing mortality at high sowing densities. The conclusion is that under these conditions plants with B chromosomes are at an advantage as compared with plants without B's. The advantage due to B's at high densities increased during the second and third growing season. The experiment demonstrates, also, that the response to selection varies among plants with different numbers of B's and varies, as well, with the age of the populations.
\end{abstract}

\section{INTRODUGTION}

A FIELD experiment by Williams (1970) provided the first indication that plants carrying B chromosomes in Lolium perenne were better able to survive than plants without B's in populations suffering high mortality due to environmental stress (see also Rees and Hutchinson, 1973). One of the factors causing high mortality was a high sowing density. That B chromosomes conferred superior fitness under high-density conditions was confirmed by Hutchinson (1975). She sowed seeds from the same population as that used by Williams in small 2-inch pots at densities of 5, 10, 25, 50, 75 and 100. The proportion of plants with B chromosomes among those surviving to maturity increased with increasing mortality at the higher densities. Because the species is perennial it was possible to continue the observations in subsequent seasons. The following is a description of the response to varying densities of plants with and without $B$ chromosomes over 3 years, showing how the survival of plants with different numbers of $\mathrm{B}$ chromosomes alters with increasing age of the populations.

\section{Material AND METHODS}

The seeds used were obtained by intercrossing plants from an Algerian population of Lolium perenne carrying B's (see Cameron and Rees, 1967). They were sown in 1972 in two replicates of ten pots each, at densities of 5, 10, 25, 50, 75 and 100 per pot. Each pot was 2 inches in diameter, $2 \frac{1}{2}$ inches deep.

The number of $\mathrm{B}$ chromosomes among survivors was determined by fixing flowering heads and scoring first metaphases of meiosis. The chromosomes are shown in fig. 1. At the higher densities each plant produced one flowering tiller only; consequently scoring tillers establishes directly the B chromosome status of the populations. At the lower densities each plant may produce more than one tiller and it is often difficult to trace each tiller to its source within a small pot. For this reason not more than two 
tillers were fixed in any one pot in 1972 and care was taken to minimise the chance of fixing tillers from the same plant. In 1973 and 1974 the "swards" within pots were even more dense and tangled and, for this reason, only one tiller was fixed from any one pot, thereby ruling out the possibility of misclassification. This precaution, along with increasing mortality, explains why fewer plants were scored in 1973 and 1974 . A "standard population" was sown as spaced plants from the same seed sample.
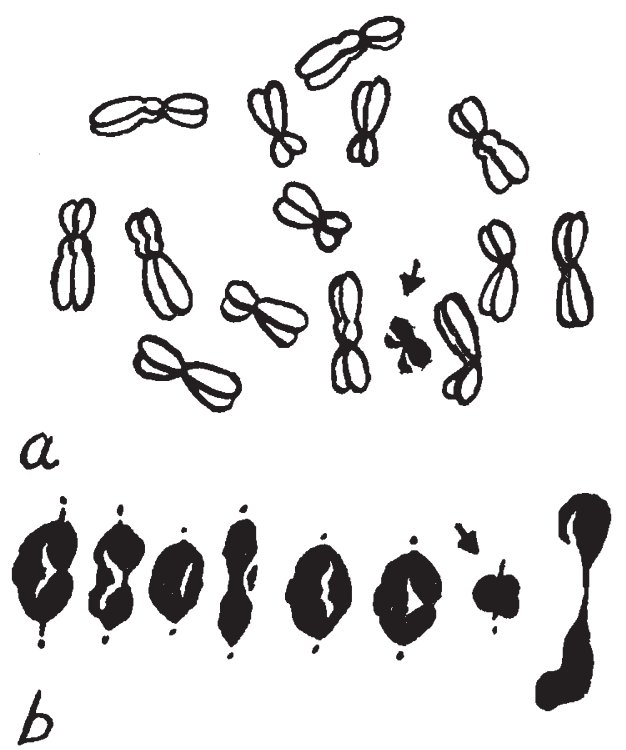

FIs. 1.- (a) Metaphase of mitosis and $(b)$ first metaphase of meiosis in a pollen mother cell of Lolium perenne $(2 n=14+1 \mathrm{~B})$. The $\mathrm{B}$ is arrowed.

Although replicates were sown the data for each year were pooled for analysis, there being no significant heterogeneity within densities within seasons.

\section{Results}

(i) Mortality

At the end of the first season 7 per cent of plants survived to flowering at a sowing density of 100,65 per cent at a density of 5 . The mortality increased over the years. In 1974 only 7,9 and 8 plants respectively survived at densities of 100,75 and 25 , i.e. between 0.4 and 1.6 per cent. At lower densities the matting of plants within pots makes it impossible to assess mortality with accuracy. There is no doubt, however, that mortality in the face of diminishing nutrients and of competition was severe at all densities and intensified from year to year.

(ii) The distribution of $B$ chromosomes among survivors

(a) Plants with and without B's

Table 1 and fig. 2 show:

1. The 1973 and 1974 results are in agreement with those of 1972 by Hutchinson; the proportion of plants with B's increases with increasing 
density. At high density (100) the proportion with B's is significantly in excess of that in the standard population $(\mathrm{P}=<0.02)$.

2. A joint regression analysis of variance, after angular transformation of the proportion of plants with B's, confirms that the increase of B's with density is significant $(P=<0.001)$. While the regressions are linear for each season the analysis also shows a significant heterogeneity in slope $(\mathrm{P}=<0.01)$. The slopes become progressively steeper from 1972 and 1974. One obvious explanation is that the proportion of plants with B's at the higher densities is much increased in 1974 relative to 1972 . In 1974 at a density of 100 only B plants remain. Figs. 2 and 3 suggest, also, that at

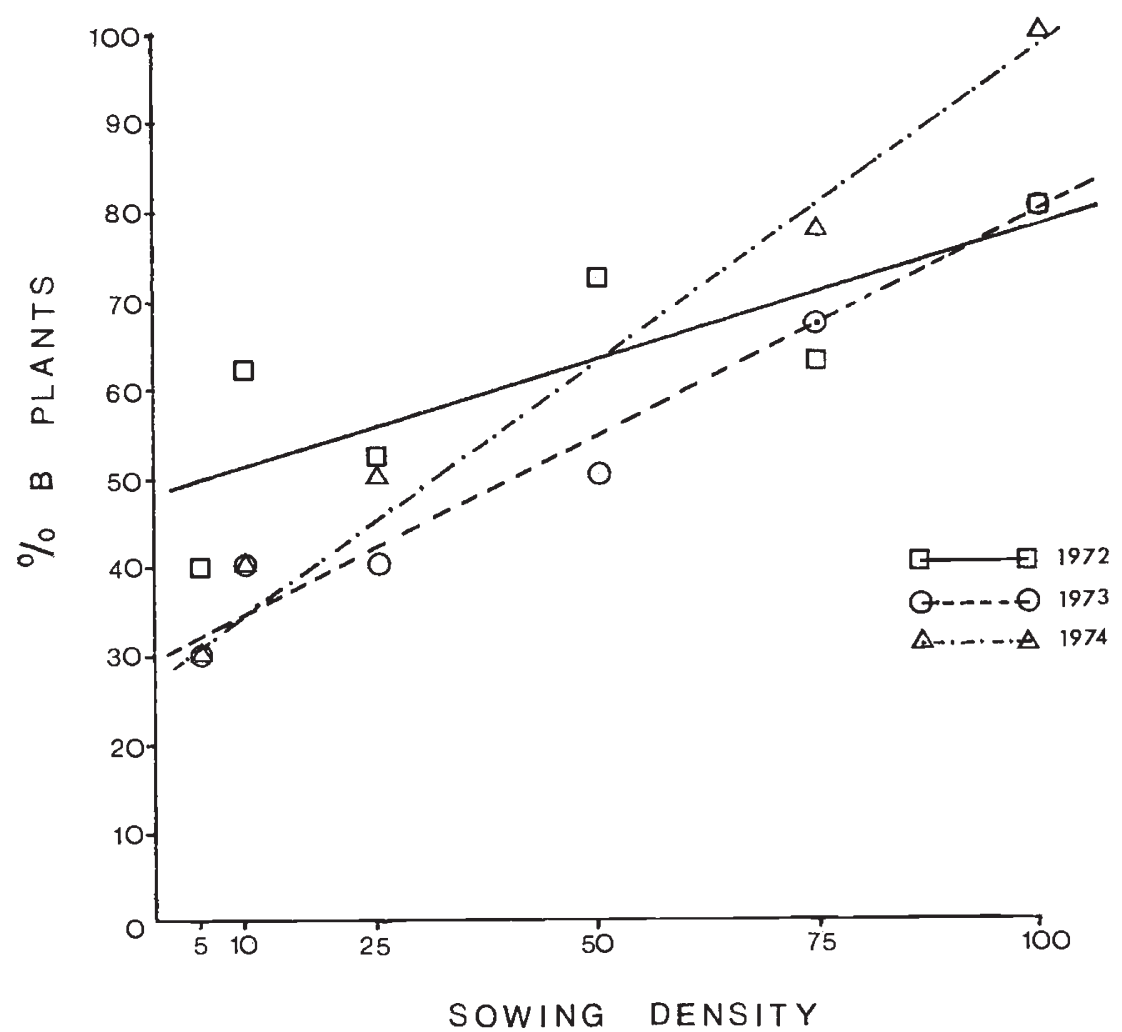

FIG. 2.-The percentage of plants with $B$ chromosomes among survivors within populations sown at different densities in 1972 . The plants were classified immediately prior to flowering in each season.

the lower densities there is a decrease in the proportion of plants with B's at the expense of those without B's between 1972 and 1974. This would imply that the effects of selection upon B's are in opposition at high and low densities and would account for the fact that the proportion of plants with and without B's in the experimental population as a whole does not vary significantly from season to season. While fig. 3 shows a drop in the proportion of plants at each of the lower densities (5, 10 and 25) during the course of the experiment we have to point out that chi-square analyses for densities separately show no significant decrease. Our interpretation must therefore remain tentative. 


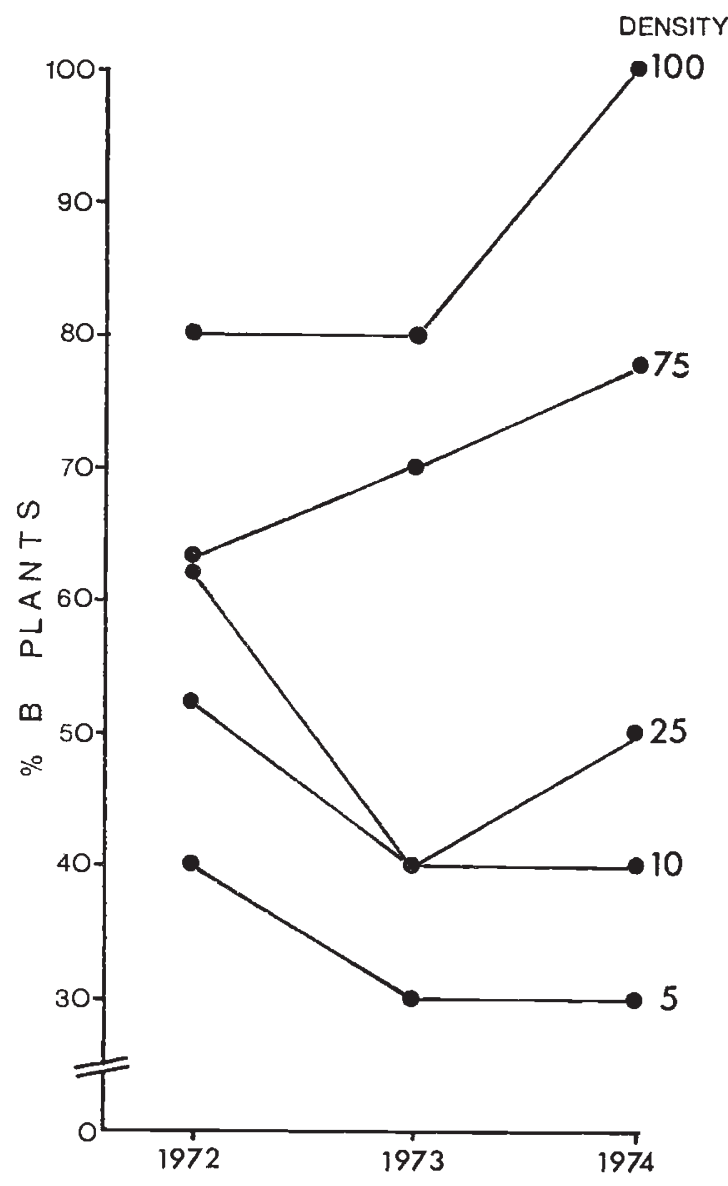

Fig. 3.-The percentage of plants with B chromosomes among survivors at different sowing densities in three seasons.

\section{(b) The distribution of $B$ frequencies}

Table 1 shows, as we would expect from the above analysis, that the mean frequencies per plant within populations show much the same trends in relation to density and season. It increases at high and decreases at low density. When we look at the distribution of plants with 1, 2 and 3 B's we find, however, that the variation among densities and seasons is not merely a matter of selection for or against plants with or without B chromosomes. In the first place there are pronounced and progressive changes in the distributions of the different $\mathrm{B}$ classes with season. The changes are reflected in table 2, which gives the frequencies of the different classes, pooled over densities, for each of the three years. The distributions are significantly heterogenous. When we compare the distributions for the "extremes", 1972 and 1974, the $2 \times 2$ contingency chi-square is 8.94 , $\mathrm{P}$ less than $<0.02$. It will be observed that the $1 \mathrm{~B}$ plants increase in proportion, those with 2 and 3 B's decrease. 
Further details of the changing pattern of variation in B classes, which are embodied in the raw data in table 1 , are illustrated in figs. $4 a$ and $b$.

TABLE 1

The distribution of $B$ chromosomes in Lolium perenne populations sown at different densities in 1972. The data were not available in 1974 for plants at a sowing density of 50

\begin{tabular}{|c|c|c|c|c|c|c|c|c|}
\hline \multirow[b]{3}{*}{ Standard: } & \multirow[b]{2}{*}{$\begin{array}{l}\text { Sowing } \\
\text { density }\end{array}$} & \multicolumn{4}{|c|}{$\begin{array}{l}\text { B chromosome } \\
\text { class }\end{array}$} & \multirow[b]{2}{*}{$\begin{array}{r}\text { Total } \\
\text { scored }\end{array}$} & \multirow[b]{2}{*}{$\begin{array}{l}\% \text { B } \\
\text { plants }\end{array}$} & \multirow[b]{2}{*}{$\begin{array}{c}\text { Mean B } \\
\text { per plant }\end{array}$} \\
\hline & & 0 & 1 & 2 & 3 & & & \\
\hline & & 22 & 12 & 15 & 1 & 50 & 56 & 0.90 \\
\hline 1972 & $\begin{array}{r}5 \\
10 \\
25 \\
50 \\
75 \\
100\end{array}$ & $\begin{array}{r}24 \\
15 \\
19 \\
11 \\
14 \\
7\end{array}$ & $\begin{array}{r}6 \\
9 \\
7 \\
10 \\
3 \\
9\end{array}$ & $\begin{array}{r}9 \\
16 \\
13 \\
18 \\
20 \\
17\end{array}$ & $\begin{array}{l}1 \\
1 \\
1 \\
1 \\
2\end{array}$ & $\begin{array}{l}40 \\
40 \\
40 \\
40 \\
38 \\
35\end{array}$ & $\begin{array}{l}40 \cdot 00 \\
62 \cdot 50 \\
52 \cdot 50 \\
72 \cdot 50 \\
63 \cdot 16 \\
80 \cdot 00\end{array}$ & $\begin{array}{l}0 \cdot 67 \\
1.02 \\
0.90 \\
1 \cdot 22 \\
1.21 \\
1 \cdot 40\end{array}$ \\
\hline 1973 & $\begin{array}{r}5 \\
10 \\
25 \\
50 \\
75 \\
100\end{array}$ & $\begin{array}{l}7 \\
6 \\
6 \\
5 \\
3 \\
2\end{array}$ & $\begin{array}{l}1 \\
2 \\
2 \\
2 \\
5 \\
3\end{array}$ & $\begin{array}{l}2 \\
2 \\
2 \\
3 \\
2 \\
5\end{array}$ & $\begin{array}{l}- \\
- \\
- \\
-\end{array}$ & $\begin{array}{l}10 \\
10 \\
10 \\
10 \\
10 \\
10\end{array}$ & $\begin{array}{l}30 \cdot 00 \\
40 \cdot 00 \\
40 \cdot 00 \\
50 \cdot 00 \\
70 \cdot 00 \\
80 \cdot 00\end{array}$ & $\begin{array}{l}0.50 \\
0 \cdot 60 \\
0 \cdot 60 \\
0 \cdot 80 \\
0.90 \\
1 \cdot 30\end{array}$ \\
\hline 1974 & $\begin{array}{r}5 \\
10 \\
25 \\
75 \\
100\end{array}$ & $\begin{array}{l}7 \\
6 \\
4 \\
2 \\
0\end{array}$ & $\begin{array}{l}2 \\
2 \\
2 \\
4 \\
4\end{array}$ & $\begin{array}{l}1 \\
2 \\
2 \\
3 \\
3\end{array}$ & $\begin{array}{l}- \\
- \\
-\end{array}$ & $\begin{array}{r}10 \\
10 \\
8 \\
9 \\
7\end{array}$ & $\begin{array}{r}30 \cdot 00 \\
40 \cdot 00 \\
50 \cdot 00 \\
77 \cdot 78 \\
100 \cdot 00\end{array}$ & $\begin{array}{l}0.40 \\
0.60 \\
0.75 \\
1 \cdot 11 \\
1.43\end{array}$ \\
\hline
\end{tabular}

From the table and the figs. we observe:

1. The disappearance of $3 \mathrm{~B}$ plants in all densities after 1972.

2. That whereas the proportion of $1 \mathrm{~B}$ plants was consistent among densities in 1972 it increased progressively at the higher densities in 1973 and 1974. Analyses confirm there is no significant regression of $1 \mathrm{~B}$ plants in relation to density in 1972 whereas in 1974 the regression is highly significant $(\mathrm{P}=<0.001)$.

TABLE 2

The distribution of plants with varying numbers of $B$ chromosomes among survivors in 1972, 1973 and 1974. Percentages in brackets

$\begin{array}{cccc} & \text { O B } & \text { 1 B } & \text { 2 B and 3 B } \\ 1972 & 90(39) & 44(19) & 99(42) \\ 1973 & 29(48) & 15(25) & 16(27) \\ 1974 & 19(43) & 14(32) & 11(25)\end{array}$

3. In all three seasons the proportion of $2 \mathrm{~B}$ plants increases with increasing density. The joint regression is significant $(\mathrm{P}=<0.001)$. While the slopes are similar the mean proportion of $2 \mathrm{~B}$ plants at all densities is lower in 1973 and 1974 than in $1972(\mathrm{P}=<0 \cdot 05)$.

To say, on the basis of these observations, that there is selection for or against plants with B chromosomes under particular environmental conditions is an oversimplification. The response clearly varies among plants with different numbers of B's and varies, also, with time. 

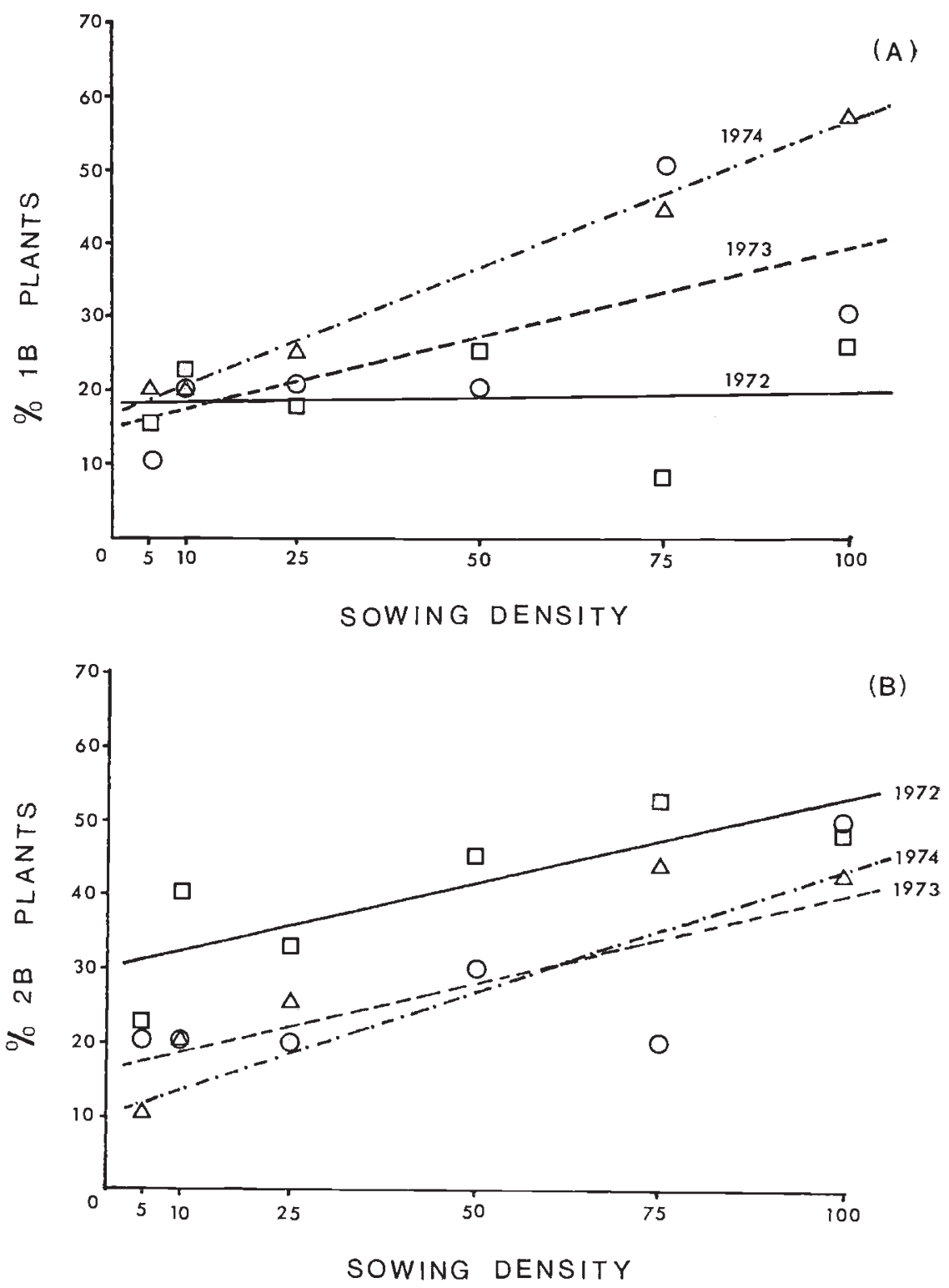

FIG. 4.-The percentage of plants with $1 \mathrm{~B}(a)$ and $2 \mathrm{~B}$ chromosomes $(b)$ among survivors in populations sown at different densities.

\section{Discussion}

(i) Interactions

The results are clear, and consistent over seasons, in demonstrating a selective advantage of plants with B's under conditions of high sowing density. Equally marked, however, are the progressively changing patterns of B chromosome variation from 1972 to 1974, for example the increasing proportion of $1 \mathrm{~B}$ plants at high densities and the decrease, relative to 
others, in the proportion of $2 \mathrm{~B}$ plants at all densities. The interactions with years could be due to many factors, the age of plants, seasonal changes in nutrient and other requirements for growth. Other possible factors are the changes in densities within populations due to mortality and, perhaps even more important, the accumulative consequences of change in the $B$ chromosome distribution itself. It will be recalled, for example, that plants with $1 \mathrm{~B}$ chromosome at high densities in 1972 were in competition with $0 \mathrm{~B}, 2 \mathrm{~B}$ and, to a lesser degree, $3 \mathrm{~B}$ plants. In 1973 and 1974 the $3 \mathrm{~B}$ plants had disappeared and, as well, most or all of the $0 \mathrm{~B}$ plants. Competition, therefore, was mainly with $2 \mathrm{~B}$ individuals. The performance of 1 B plants may, in this new company, be very different. The same argument applies to other B categories in competition at other densities in the different seasons. Although the various interactions with season to which we have referred are, in this experiment, confounded and therefore not separable it is well to emphasise that they apply not only between genotype and the seasonal change in environment but also between genotypes in varying combinations.

(ii) The $B$ frequency

While the effects of selection at different densities are clear enough in each of the three years, we pointed out that when the frequencies of plants with and without B chromosomes were summed over densities in each year the distributions did not differ significantly from one another and, moreover, did not differ from that of the standard, control population. These facts are worth considering in relation to natural populations. There is good evidence that a stable equlibirium in respect of B frequency applies within natural populations in many species (e.g. Hewitt, 1973). Within any one natural habitat there is inevitably a range and, often, a substantial variation in the range of environments whether it be in micro-climate, soil type, shelter or in a host of other factors. We suggest that one factor promoting the equilibrium is a selection for $\mathrm{B}$ chromosomes in a restricted part of that habitat and for individuals without B chromosomes in others, much as applies to the different densities in the present experiment.

\section{ReFERENGeS}

CAMERon, F. M., AND REEs, H. 1967. The influence of B chromosomes on meiosis in Lolium. Heredity, 22, 446-450.

HEWITT, G. M. 1973. The integration of supernumerary chromosomes into the Orthoptera genome. Cold Spring Harbor Symp. Quant. Biol., 38, 183-194.

Hutchinson, J. 1975. Selection of B chromosomes in Secale cereale and Lolium perenne. Heredity, 34, 39-52.

REEs, H., AND hUtChinson, J. 1973. Nuclear DNA variation due to B chromosomes. Cold Spring Harbor Symp. Quant. Biol., 38, 175-182.

williams, P. 1970. Genetical effects of B chromosomes in Lolium. Ph.D. thesis. University College of Wales. 